\title{
Community Attitudes towards Child Sexual Abuse: A Case of Chawama Lusaka, Zambia
}

\author{
Kabwe Chitundu*, Lonia Mwape, Concepta Kwaleyela \\ School of Nursing Sciences, University of Zambia, Lusaka, Zambia

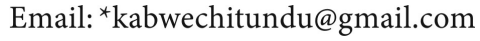

How to cite this paper: Chitundu, K. Mwape, L. and Kwaleyela, C. (2020) Community Attitudes towards Child Sexual Abuse: A Case of Chawama Lusaka, Zambia. Open Journal of Psychiatry, 10, 25-37.

https://doi.org/10.4236/ojpsych.2020.101004

Received: July 24, 2019

Accepted: January 16, 2020

Published: January 19, 2020

Copyright (อ 2020 by author(s) and Scientific Research Publishing Inc. This work is licensed under the Creative Commons Attribution International License (CC BY 4.0).

http://creativecommons.org/licenses/by/4.0/

\begin{abstract}
Background: Child sexual abuse continues to be an issue of great concern and recognized as a public health problem in Zambia. Hence the study examined community attitudes and beliefs that shape communities perceptions towards child sexual abuse, the interaction between adults and children which consequently hinder reporting of child sexual abuse cases. Methods: A qualitative study design was employed. Nine focus group discussions (FGD) with 49 participants comprising 5 to 6 participants in each FGD and nine indepth interviews guided by an interview guide were used to collect data. Participants were selected using purposive sampling. The collected data were transcribed verbatim and analyzed using thematic analysis. Results: Two major themes namely: 1) Defilement, an unacceptable yet concealed phenomenon, and 2) Parental negligence as a major contributor to child sexual abuse, emerged from the data. Participants highlighted that communities regarded child abuse to be necessary for reported only if the abused child was less than 5 years old, a female, and if the trauma the child was subjected to was severe. This was because older girls were seen to be able to have consensual sex, and boys were traditionally viewed as being strong and thus, not report most cases. Parents were also seen to be losing control over their children as most of them were involved in excessive alcohol intake, leading to failure in managing their children. Poverty was another aspect reported to have led parents to send their children into prostitution. As a result parents could not report, as they felt they partly contributed to their children being sexually abused. Conclusion/Recommendations: The study showed that communities do not accept child sexual abuse, but yet they were reluctant to report the cases. It is imperative therefore, that communities learn the importance of reporting sexual abuse cases; as failure to report is risky behavior that can put the abused child and others at risk of other negative vices too.
\end{abstract}

\section{Keywords}

Child Sexual Abuse, Attitudes, Community 


\section{Background}

Child sexual abuse has become a health concern in Zambia. Child sexual abuse has been defined differently by several authors even though there exists a common consensus amongst clinicians and researchers stating that it is a social problem globally [1]. However, it is noted that even though the number of cases is on the increase a lot of cases still remain unreported. Understanding public attitudes regarding child sexual abuse (CSA) is important, as attitudes can affect reporting child abuse and consequently interfere with the prosecution of the perpetrators [2]. In Tanzania, a study by [3] showed that people still had accepting behaviours towards sexual violence, and participants with increased knowledge had less accepting attitudes towards sexual violence. However, rape myths and stereotypes are still accepted, believed and propagated by many communities.

Studies show that female respondents usually believe the sexually abused child is not to blame, and hence, view adult-child interactions as precursors. However, men on the other hand tend to blame the child, and rate adult sexual interactions as less abusive. A conservative and patriarchal view of women as opposed to a modern view of women, is positively correlate with accepting attitudes towards adult child sexual abuse [4].

Some myths on child sexual abuse place children at a disadvantage, as some communities believe that it is not abuse if it does not bring harm to the abused child [5]. This even gets worse in cases of incest victims, as they are often placed in myths that put positive spins on child sexual abuse such as the children experience love, pleasure, and physical affection for the perpetrator [6]. Despite numerous researches providing evidence indicating that child sexual abuse is harmful, there are some scholars who support the myths of harmlessness [7].

Rape myths and stereotypes are still accepted, believed and propagated in certain communities. In Tanzania, a study by [3] showed that people still had accepting behaviors towards sexual violence, and participants with increased knowledge had less accepting attitudes towards sexual violence Commonly accepted rape myths include: "girls deserved to be raped; she asked for it through her provocative behavior or dressing; and there was not much physical damage, so it was not really rape" [8].

The incidence of child sexual abuse is seen to be on the increase partly due to community attitude of accepting myths such as human immune virus and acquired immune deficiency syndrome (HIV/AIDS) sufferers being cleansed after they have intercourse with children [3] [9]. Parents are also believed to be playing an important role in protecting and preventing their children from getting sexually abused [3] This study intended to explore the attitudes of the community towards child sexual abuse with the view of highlighting non-reporting of cases and community awareness and sensitization on child sexual abuse.

\section{Method}

This was a qualitative study comprising of 49 community members. The study 
site was an urban slum settlement called Chawama in Lusaka, the capital of Zambia. The study used both focused group discussions and indepth interviews selected through purposive sampling technique. The community entry was through sensitization of the study to the faith based organizations, schools, market places, community groups and local authorities. These were engaged to help with community sensitization to would be participants of the study. The participants were mainly found on Shantumbu market day which is a day when the vegetables are cheap and a lot of people go to buy from the market and this day is held on Monday and Friday. Those that were willing to participate were scheduled for consenting. Further, participants who verbalized having a victim who's a relative and consented to participate were later scheduled for an indepth interview which was done one on one with the researcher. Ethics approval was sought from the University of Zambia Biomedical Research Ethics Committee (UNZABREC).

\section{Sample Size}

The sample size was determined by data saturation. This means that data continued to be collected until no new themes were emerging. All consenting participants were included to participate in the focused group discussions, then for the in-depth interview the sample size was dependent on the participants from the focused group discussion who were relatives to the victims and further consented to participate in the study. The final sample size was:

Focused group discussion interview $=49$ ( 9 groups).

Indepth Interviews $=9$.

Total Sample Size $=49$.

\section{Study Protocol}

Data was collected from March to May, 2017. Community entry was through sensitization of the study to faith based organizations, schools, market places, community groups and local authorities. These were engaged to help with community sensitization to would-be participants of the study. All consenting adults aged 18 years and above were included in the study.

\section{Statistical Methods}

Data analysis was through thematic analysis. Data was transcribed and verbatim. Responses were coded and data were repeatedly compared with responses from various groups to prevent shift in meaning. Finally, interpretation was undertaken with an attempt made to theorize the significance of the patterns in relation to the respective research objectives. Two major themes were drawn, with each having sub-themes.

\section{Results}

Major Theme: Defilement, an unacceptable yet concealed phenomenon

This theme emerged from the information that defilement cases were a com- 
mon occurrence, yet it was only reported when it was regarded to be serious in the reporters view. The theme was informed by three subthemes namely: 1) Gender of the child 2) Age of the child, and 3) Severity of the trauma.

\section{Gender of the Child}

This subtheme explained the defilement phenomenon by reflecting the behavior communities had towards reporting of abuse cases of both girls and boys. It elucidated that defilement cases were reported depending on the gender of the defiled child. Most of the participants who had heard of boy child defilement reported that the vice was often not reported due to lack of physical injury to the child. Participants spoke of a reaction of shock upon hearing that a boy child had been defiled. Twenty-five years old Mr BM expressed his reflection as follows:

"Boy child rape... it is difficult to report... in the first place the penis is small and there will be no bruises so what evidence will one present to the police and hospital' (Mr BM)

Unlike Mr BM who did not have close any experience of boy child defilement; Mr PT who had his son defiled by his sister inlaw also narrated similar feelings. He said:

"When I discovered that my son was being abused by my sister inlaw... at first I had no evidence and thought my son was just lying until I caught them red handed that's when I believed what my son was saying" (Mr PT)

Other participants reported that boy child rape was often not reported because men by tradition were expected to be strong and hence, do not express their weaknesses in public. Therefore, in trying to show that they are strong, most male children hide that they have been abused Mr AN said:

"Mwamuna afunika kunkala olimba osati kulilalila mubantu (a man is expected to be strong and not cry anyhow in public)..." (Mr AN)

Similar thoughts of the community's perceptions of boys as being strong were expressed by most married men. They stated that it is the training that male children go through, which discourages them from reporting everything that happens to them. This is presumed to mould them into strong men in future. Twenty-five year old Mr PL reported:

" $A$ man should be strong and if a boy is reporting everything even irrelevant things that one is not likely to make a good husband in future because they can't make decisions on their own. It simply shows he is a weak man" (Mr PL)

However, in Mr. PT's son's case, he explained that his son reported the abuse to him because he was still very young, and at years he was at a stage when children talk a lot.

In a similar context, the community's perception was that girls of puberty age were ready for marriage, and therefore, it was not necessary to report to the police if they are defiled. Instead, some participants revealed that in such instances, the defiler and the defiled were often encouraged to get married, and the man charged for damage and later on dowry. Thirty-one year old, Mrs HN stated: 
"It does not make sense to report that a girl who is of age has been defiled because she is ready to be a mother..." (Mrs HN).

Some participants explained that defilement was sometimes condoned by community members because there was an accepted expression that "adya kake alibe mulandu"; translated as "he who eats from his own has no problem". Thus for Mr EM, his thoughts were that there was no harm in defiling one's relative. He said:

"Adya kake alibemulandu! Why should one be punished for eating from his own? People can complain if it was a stranger. (Mr EM).

However, most females were not in agreement and hence condemned the vice. They expressed that defilement was a bad practice regardless of who committed it, the gender of the victim, and whether there were physical injuries or not. However, they concurred with their male counterparts and reported that defilement by a stranger was more serious and parents should make sure the perpetrator received severe punishment, while that of a family member could be concealed at times.

\section{Age of the Child}

As mentioned in the major theme, the defiled child's age was a factor that influenced the way a defilement was viewed. If the defiled child was below five years, it was categorized as severe. Most participants felt that abuse of children below five years ought to be treated with seriousness and reported to the police as soon as possible. For most participants, a perpetrator who abused a child below five years was a threat to society. This is how Mrs ER expressed herself:

"It is unimaginable that a normal person can have sexual intercourse with a child below five years because what satisfaction can such a person get from a child'. (Mrs ER)

Furthermore, most participants attributed sexual abuse of children to the selfish nature of people; for instance, someone wanting to get rich or cured of HIV and sexually transmitted infections. Mental illnesses were also attributed to child sexual abuse. It was reported that most people desired to get rich, hence, they sought help from traditional healers who then instruct them to have sexual intercourse with children, usually below the age of 12 because it is believed they are innocent. The perception is that blood that comes out after intercourse with a child brought good luck to businesses. It is also believed that such rituals did not work well when the defiled person is an adult. Mr LP said:

"Child sexual abuse is perceived as a cure for STI, mental illness and HIV and also considered as a lucky charm for business people. A traditional healer will tell you to have sex with a young girl if you want to prosper in your business or to get treated of sexually transmitted disease, mental illness or HIV/AIDS" $(\mathrm{Mr}$ LP)

It was further reported that people who abused children below five years were considered to be evil, and using them evil motives. Mrs MK stated that it is evil and Satanic to have sexual intercourse with a child. This is how she expressed 
herself:

"It was unimaginable to see my 3 year old daughter defiled by my husband $s$ young brother and I kept thinking what was really going on in his mind. Honestly this is pure evil and an act of Satanism". (Mrs MK)

Additionally, some participants reported that most men perceived that younger girls were warmer and had tighter vaginas as compared to older ones who had given birth before. Thus, by implication, men did not enjoy sexual intercourse with their wives because they were adults. A 27 year old Mr KP expressed himself like this:

"Sex with a child ohooo... u know I haven't done it before but am sure a child is much tighter than a person who has given birth before. And it becomes worse when a woman has more than 3 children the vagina really becomes big. So am very sure children have tighter vaginas." (Mr $\mathrm{KP})$.

Physical trauma subjected to the child

The third subtheme: "physical trauma subjected to the child" expounded another feature that warranted a defilement case to be reported. Most participants reported that when a child presented with severe physical injuries, such as inability to walk, severe bleeding from the private parts, injuries/bruises to the genitalia, and development of a fistula, the defilement was regarded as severe and needed to be reported to the police. Mrs MK said:

"Hmmmmmmm. It is really tricky to report without any form of evidence. I think you only report if the child is bleeding because you have evidence. Otherwise without bleeding no one will believe you the police can even chase you from the centre". (Mrs MK).

Some participants reported that they felt health care was reserved for severe injuries or when survivors required forensic evidence to pursue legal actions. Thus, if a child did not have evidence of physical injuries parents failed to report the cases or seek medical help. Mrs MM said:

"Hmmmmmm it is really sad because if a child has been abused for a long time the parents have no evidence and cannot even go to the hospital because no one will attend to them as some nurses will think they are lying". (Mrs MM).

Some participants spoke of the behavior of a child after the abuse as an aspect that can lead to reporting. They stated that if a child has been sexually abused and they do not seem to be affected it could mean that the abuse has been going on for a long period, and most likely the child had started enjoying it. Therefore, it was felt that there was no need to report. However, if a child seemed to be affected, the case was to be reported to the police. Mrs MK narrated:

"If a child is bleeding or failing to walk it shows that it is happening for the first time but when the child acts normal it is possible that they would have started enjoying the sexual acts especially if they have become of age". (Mrs MK).

Most participants reported that young children nowadays were sexually active by the age of 12 years, thus, it was difficult to know whether one was forced or 
not, especially if there were no signs of physical injuries. This was therefore, making it difficult for parents to report sexual abuse cases. They explained that when child was abused after she had already lost her virginity it was very difficult to win the case without physical evidence of the perpetrator's semen. Mrs DK said:

"Am telling you it is really sad. My daughter was abused when she was 13 years old but she had already lost her virginity by then. And to make matters worse, she came home straight and bathed after she was defiled; so we had no evidence to prove she had been defiled and we ended up not reporting and sadly the perpetrator died a year after". (Mrs DK)

Theme 2: Parental negligence as a major contributor to child sexual abuse

The second theme; "Parental negligence as a contributor to child sexual abuse" defined the way parents took care of their children. It was felt that some of the ways predisposed children to sexual abuse. The theme was constituted by three sub-themes namely; 1) Heavy alcohol intake by parents 2) Parents' lack of control, and 3) Prostitution.

\section{Heavy alcohol intake by parents}

The subtheme; "heavy alcohol intake by parents" was defined by the ways in which parents were engaging themselves in alcohol intake in relation to the negative influence on the care given to children. Some participants reported that alcohol intake was a major concern in their communities, which put children, especially girls at risk of sexual abuse. They reported that most parents made drinking beer every day to be a routine. They further, reported that this negative vice was becoming worse because women had joined more especially when attending kitchen parties; leaving no one to protect the children. Mrs LN and LK expressed themselves this way:

"Child sexual abuse cases are really sad to even start talking about, my elder sister's child was being abused by her step father when she was out drinking with her friends, because most of the times she would be too drunk to even notice that her child was being abused". (Mrs LN)

"There is too much alcohol intake when women go for kitchen parties, as a result no one takes care of children, and they can easily be sexually abused". (Mrs LK)

Mr MK, a 28 year old man explained that most women were being initiated into the habit of beer drinking as they start attending kitchen parties. He reported that it was surprising to observe how women were attending kitchen parties every weekend and leaving their children unattended or being looked after by males.

Participants also reported that alcohol makes one to lose self-control, and as a result, when men and women take alcohol they lose control and at the worst even become capable of grabbing children and defiling them. Due to alcoholism most women had become absentee parents. They are thus never there to monitor and mentor their children, hence, putting them at risk of abuse. Due to many 
mothers being frequent absentee parents, most perpetrators know the time they can go and abuse the children.

\section{Parents' lack of control}

The subtheme "parent's lack of control" defined the ways in which parents were failing to control their own behaviours, and hence putting their children at risk of sexual abuse. Some participants reported that parents' lack of control was worrying. For instance; because of the absentee female parent syndrome, children were involving themselves in indecent dressing, which put them at risk of sexual abuse. They acknowledged that indecent dressing by underage children had become rampart, and the body morphology of a 13 year old was no different from a 23 year old. Thus, they too were equally attracting men and putting themselves at risk. Mrs $\mathrm{RN}$ remarked:

"My sister's daughter was defiled by her husband's young brother because of her indecent dressing as parents could not control her because they were never home. She would wear bum shorts and revealing tops which made her appear attractive in her uncle's eyes and consequently predisposed her to sexual abuse". (Mrs RN)

It was intriguing to learn that irrespective of one's educational level or social status, participants expressed deep concern about indecent dressing. Most participants tried to adhere to traditional practices even though at times they did not comprehend the reasoning behind; for example the use of wrappers called vitenge in Zambia, every time a female was at home. Mr LP said:

"When we were growing up girls always used to wear vitenges when home to cover their bodies and as a sign of respect and dignity to herself and her family but nowadays most of the girls have abandoned the old descent ways of dressing and want to model what they see on social media which is unacceptable in our African culture". (Mr LP)

Although the majority of the participants criticized some of the old traditions and considered them outdated, some traditional practices such as putting on decent clothing such as vitenges to cover a girl's body were still considered valuable. Participants also reported that children nowadays were too free with their parents, making it difficult for parents to exercise control over them. They reported that in their time when their parents were watching television in the sitting room, children were supposed to go and sleep. However, this was no longer the practice due to over familiarization with parents. This predisposed children to be sexually abused. Mrs MK said:

"In our time it was not right to be in the sitting room watching $T V$ with your parents and we always ensured that we left the place when they come to show respect and not what we are seing today. Children even hold the remote control and want to watch what they want and not what the parents want'. (Mrs MK)

\section{Prostitution}

This subtheme reflected women's engagement in illicit sexual behaviors in order to provide their children's basic needs. Most participants expressed con- 
cern that in relation to beer drinking most of the women also involved themselves in prostitution as a way of livelihood. Some female parents were themselves prostitutes, and thus they saw nothing wrong in sending their children into prostitution as a way of earning a living. participants also expressed concern that some of the girls who are sexually abused had mothers who are prostitutes, giving an impression that the mothers did not see anything wrong. They instead regarded the sexual abuse it is a way of preparing the child to become better in bed, so that she or he could handle any future sexual encounter with ease and be able to bring money to help at home. This is how Mr KP expressed himself:

"Some women even say leave my child alone because am a prostitute and am earning money to take her to school. Look at you who's not a prostitute are you even able to feed your children. And by the way most prostitutes make a lot of money and are able to eat well and take children to school so it is difficult to convince them to stop". (Mr KP)

Most participants attributed prostitution to the poor economic status of most families. They reported that due to poor economic status parents leave their children to provide for themselves; children start soliciting for help from elderly men who can provide them with all their needs in exchange of sexual favors.

"Very often we see parents and guardians especially grandparents sent their daughters into prostitution so as to earn a living and contribute to the family and sometimes girls want a life the parents cannot afford so they resort to prostitution at an early age". (InitialSome participants reported that in certain instances, in order to supplement food security in homes, parents send their children in the streets to sell food stuffs. This practice makes the children to be vulnerable to sexual abuse. Mrs NP and IN said:

"Parents send their children in the streets to go and sell food stuffs like fruits or bread and this makes them at risk of being abused". (Mrs NP)

"Parents should stop sending children on the streets to sell food stuffs because some men have no self-control due to alcohol intake and are likely to abuse the children". (Mrs IN)

\section{Discussion}

This study aimed at exploring the attitudes of the community towards that consequently hinder the reporting of cases. The communities portrayed displeasure in the sexual abuse act and ability to accept that child abuse was a bad practice. Age, gender, physical trauma, and parental negligence were seen as contributing factors to communities' inability to report defilement cases. Most participants ascribed to the view that child sexual abuse was a common and unacceptable yet hidden occurrence in the community. They stated that although it was common. It was only reported when it was regarded serious. The reasoning behind whether to report or not report was based on whether the perpetrator was a family member or a stranger. If the perpetrator was a stranger then it was considered serious; if it was a family member it was not considered that serious because the 
perpetrator would receive their punishment from the family members. The findings are similar to a previous study done by [3], which demonstrated that when the perpetrator was a family member, child sexual abuse cases were dealt with covertly.

There was a belief, mostly from men that he who ate from his own had no case, hence some men did not recognize as a bad practice. However, most women considered it to be bad and very traumatic to the child, and therefore, they advocated that perpetrators should be severely punished regardless of their relationship with the victim. In contrast to this belief, a study by [10] showed that defilement by a parent was regarded as more severe and traumatic to the child, and the relationship between perpetrator and victim did not affect the perception of. The difference in opinion between men and women illustrated the influence of gender on the vice.

It was observed that cases were often reported when the child involved was below 5 years, while those involving children older than twelve were regarded as not serious and not often reported because the affected children over were regarded as mature with the ability to make sound decisions. Therefore, when a child above 12 years old was sexually abused, it was sometimes thought that the abuse was an agreement between the adult and the child. The findings are similar to a study done by [2] [3], with the latter revealing that scenarios of a 15 years old were rated as less abusive, and less responsibility was attributed to the adult involved; whereas defilement of a 7 years old was considered very serious, and the adult was blamed for the abuse. These findings suggest that age of the child may influence the ratings of abusiveness and attribution of responsibility and blame, and also showed that age of the child influenced whether abuse was to be reported or not.

Furthermore, participants stated that child sexual abuse cases were reported when there was severe physical trauma to the child, with evidence such as bleeding or failing to walk among others. The representation of as a bad practice was also mentioned by [3] [10]. On the other hand, a study conducted in Pakistan showed that one third of men did not consider child sexual abuse as bad and that there was a belief that if people did not see what you were doing then your behavior was accepted [3]. A study by [5] showed that child sexual abuse was not actually abuse and that it was not harmful [11] also supported the myth of harmlessness. Support for these myths not only denies the personal trauma to and the public health problem but also serves to benefit the pedophiles.

Inadequate care from the parents to their children contributed to the increase in the child sexual abuse cases. Participants stated strongly that children who are left alone without supervision of the parents were more likely to be abused. It was further, reported that parents who were involved in heavy alcohol consumption consequently increased the chances of their children being defiled because there was lack of care for the children. The study findings are in line with [3] who explains that beer drinking situations were worse in perpetuating the vice 
when the women attend for the kitchen parties frequently. The behavior of women drinking could be attributed to the gender equality where women are much freer to express themselves.

Prostitution, which was due to poverty in the community has also led to the increase in abuse cases and put victims in a weird positions because parents were not sure whether they were fit to report the abuse. Poverty was a major restraint in not only accessing care and meeting the expenses of care, but also rendered children to be victims of. Poverty made children more vulnerable to prostitution as they solicit for financial and material support. Some parents were reported to be in the habit of sending their children onto the streets to go and sell food. This consequently predisposed them to child sexual abuse because streets are frequented by people with different motives. Further, some parents and guardians send their children onto the streets to exchange sex for money as a mode of survival for young children. The representation of poverty and poor economic status as contributing to the increase in child sexual abuse has also been reported by [3] revealing how some mothers were prostitutes and thus considered the vice as a way of earning a living. Such parents saw nothing wrong in sending their children on the street for prostitution irrespective of the higher chances of being defiled.

Some study participants believed that most mothers were to blame for their children's sexual abuse because of to their carelessness and lack of responsibility. In cases where a child was sexually abused by a rich person most parents opted to obtain money from instead of reporting the case to court because of poverty. This gave the impression that to some parents how much money they got from the perpetrator was paramount to the psychological health of their child and the impact of the trauma. These findings are in line with previous researches conducted by [12] [13] that associated poverty with people's vulnerability to receive money from perpetrators. [5] further states that poverty drives certain families to use their children as sex workers in order to meet their basic needs.

Inadequate care of the parents to their children was also seen in the indecent dressing by most children, and this was seen as a contributing factor to cases. Participants stated that some parents are too busy to stay at home and monitor what clothes their children are putting on. They stated that children put on very tight and revealing clothes which made them attractive to men and consequently predisposing you them to. Similar findings are reported by [3] who further states that indecent dressing attracts men especially if they are drunk; they can lose self-control and abuse the child.

Lastly, some participants blamed women for sexual abuse cases due to their negligence and the element that women sometimes turned a blind eye when their partners and family members had sex with their children. The participants viewed such women as having failed to protect their children. The findings are in line with previous research findings from [14] in the United States of America who also stated that the community had little empathy on mothers of sexually 
abused children because they were seen as having failed to protect their children.

\section{Conclusion}

The implication of child sexual abuse in many parts of the world can be unpleasant for the child affected, but tends to be extended to the family as well. Parents affected children too need support because they carry the shame together with the victims. The study findings indicate a great need for attitudinal change towards reporting of child sexual abuse cases no matter the circumstance. The findings have potentially important implications for the interventions aimed at preventing children from sexual abuse as this is a major public health concern. There is a serious need to empower parents as this will make them better able to take care of their children

\section{Limitations of the Study}

Focused group discussions had a lot of people which made people uncomfortable to partipate as the nature of the nature of topic is very sensitive. Resources could not allow the study to be conducted on a large scale because the project was not adequately funded and therefore, the site was conveniently selected.

\section{Acknowledgements}

We would like to acknowledge the financial support provided by the Norwegian Agency for development (NORAD) through the NORHED QZA 0848QZA-MW13/00032 Grant.

\section{Conflicts of Interest}

The authors declare no conflicts of interest regarding the publication of this paper.

\section{References}

[1] (2003) Sexual Abuse of Young Girl's Life in Zambia. Agence France-Press.

[2] Marynard, C. and Weiderman, M. (1997) Undergraduate Students Perception of Child Sexual Abuse: Effects of Age, Sex, and Gender-Role Attitude. Child Abuse and Neglect, 21, 833-844. https://doi.org/10.1016/S0145-2134(97)00045-8

[3] Abeid, M., Muganyizi, P., Olsson, P., Darj, E. and Axemo, P. (2014) Community Perceptions of Rape and Child Sexual Abuse: A Qualitative Study in Rural Tanzania. BMC International Health and Human Rights, 14, 23. https://doi.org/10.1186/1472-698X-14-23

[4] Johnson, C.F. (2004) Child Sexual Abuse. Lancet Review, 364, 462-470. https://doi.org/10.1016/S0140-6736(04)16771-8

[5] Collings, S.J. and Madu, S.N. (2002) The Prevalence and Characteristics of Child Sexual Abuse among South African University Students. South African.

[6] Tamarack, L.I. (1986) Fifty Myths and Facts about Child Sexual Abuse. In: Schlesinger, E., Ed., Sexual Abuse of Children in the 1980's, University of Toronto Press, Toronto, 3-15. https://doi.org/10.3138/9781487583392-002 
[7] Cromer, L.D. (2006) Factors That Influence the Believing of Child Sexual Abuse Disclosure. USA.

[8] Carmody, D.C. and Washington, L.M. (2001) Rape Myth Acceptance among College Women: The Impact of Race and Prior Victimization. Journal of Interpersonal Violence. https://doi.org/10.1177/088626001016005003

[9] Kisanga, F., Nyastrom, L., Hogan, N., Mbwambo, J., Lindmark, G. and Emmelin, M. (2010) Perceptions of the Child Sexual Abuse-A Qualitative Review Study with Representatives of the Socio-Legal System in Urban Tanzania. Journal of Child Sexual Abuse, 19, 290-309. https://doi.org/10.1080/10538711003789031

[10] Bornstein, B.H., Kaplan, D.L. and Perry, A.R. (2007) Child Abuse in the Eyes of the Beholder: Lay Perceptions of Child Sexual and Physical Abuse. Child Abuse and Neglect, 31, 375-391. https://doi.org/10.1016/j.chiabu.2006.09.007

[11] Putnam, F.W. (2003) Ten-Year Research Updates Review: Child Sexual Abuse. Child Adolescent Psychiatry, 269-278. https://doi.org/10.1097/00004583-200303000-00006

[12] Mukuka, L. and Nevo, V.S. (2007) Child Abuse and AIDS-Related Knowledge, Attitude and Behavior among Adolescents in Zambia. Child Abuse \& Neglect, 31, 143-159. https://doi.org/10.1016/j.chiabu.2006.08.006

[13] Kamuwanga, C. and Ngoma, C.M. (2015) Perception of Child Sexual Abuse among Convicted Prisoners in Zambia. University of Zambia, Lusaka.

[14] Russel, D. (1984) Sexual Exploitation, Rape, Child Sexual Abuse and Workplace Harrasement. Sage, Beverly Hills. 